Article

\title{
Facile Synthesis of Silver-Doped Zinc Oxide Nanostructures as Efficient Scaffolds for Detection of p-Nitrophenol
}

\author{
Deepika Thakur ${ }^{1}$, Anshu Sharma ${ }^{1}$, Dharmender Singh Rana ${ }^{2}$, Nagesh Thakur ${ }^{2}$,

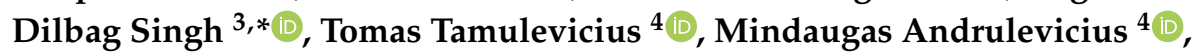 \\ Sigitas Tamulevicius ${ }^{4}\left(\mathbb{D}\right.$, Sudheesh K. Shukla $5,6,7, * \mathbb{1}$ and Sourbh Thakur ${ }^{4,8, *}$ \\ 1 Department of Physics, Maharaja Agrasen University, Solan 174103, HP, India; \\ dpikathakur@gmail.com (D.T.); dranshusharmamau@gmail.com (A.S.) \\ 2 Department of Physics, Himachal Pradesh University, Gyan Path, Summer Hill, Shimla 171005, India; \\ dharmenderrana26@yahoo.co.in (D.S.R.); ntb668@yahoo.co.in (N.T.) \\ 3 Department of Environment Science, Central University of Himachal Pradesh, Dharamshala 176206, India \\ 4 Institute of Materials Science, Kaunas University of Technology, K. Baršausko St. 59, \\ 51423 Kaunas, LT, Lithuania; tomas.tamulevicius@ktu.lt (T.T.); mindaugas.andrulevicius@ktu.lt (M.A.); \\ sigitas.tamulevicius@ktu.lt (S.T.) \\ 5 School of Environmental Science and Engineering, Shandong University, Jimo, Qingdao 266237, China \\ 6 Institute of Advanced Materials, IAAM, 59053 Ulrika, Sweden \\ 7 VBRI, 7/16 Kalkaji Extn., New Delhi 110019, India \\ 8 School of Chemistry, Faculty of Basic Sciences, Shoolini University, Solan 173229, HP, India \\ * Correspondence: dbrana@cuhimachal.ac.in (D.S.); sudheeshkshukla010@gmail.com (S.K.S.); \\ thakursourbh@gmail.com or sourbh.thakur@savba.sk (S.T.)
}

Received: 22 August 2020; Accepted: 30 October 2020; Published: 3 November 2020

\begin{abstract}
In this paper, silver-doped zinc oxide nanoparticles were synthesized by using a solution combustion technique, in which zinc nitrate is used as an oxidizer and tartaric acid as a fuel. The phase composition, morphology and structural properties of the as-synthesized zinc oxide and silver-doped zinc oxide were established by using powdered $X$-ray diffraction, field emission scanning electron microscopy coupled with energy-dispersive X-ray spectroscopy, and X-ray photoelectron spectroscopy studies. Due to well-defined morphologies and crystallinity, the pure zinc oxide and silver-doped zinc oxide nanostructures can be used as efficient chemical sensors for the detection of p-nitrophenol (PNP). $\mathrm{ZnO}$ was found to show a low value of the limit of detection (LOD), i.e., $2.175 \mu \mathrm{M} / \mathrm{L}$, for p-nitrophenol sensing; moreover, a sharp decrease in the limit of detection was observed with an increase in the concentration of silver ions, and the LOD value decreased to $0.669 \mu \mathrm{M} / \mathrm{L}$ for $10 \mathrm{~mol} \%$ silver-doped zinc oxide. It is therefore concluded that Ag-doped $\mathrm{ZnO}$ shows a lower limit of detection as compared to pure $\mathrm{ZnO}$ for $\mathrm{p}$-nitrophenol sensing.
\end{abstract}

Keywords: Ag-doped $\mathrm{ZnO}$; solution combustion; luminescence; p-nitrophenol sensing

\section{Introduction}

Rapid industrialization and various anthropogenic activities have led to the discharge of various types of toxic chemicals, which contaminate the environment and adversely affect the ecosystem. Among various toxic chemicals, the nitrophenols and organic dyes are the most emerging environmental pollutants. In particular, p-nitrophenol (PNP) is commercially very useful and finds application in various fields such as use as an intermediate in the synthesis of paracetamol and an important base material for the synthesis of commonly used pesticides such as acetophenetidine; it also plays an 
important role in the leather industry, etc. [1-3]. The release of PNP into the environment takes place through a number of ways, such as release as a side product of many pharmaceutical industries, the disintegration of other pesticides and the transformation of phenol into nitrophenol molecules. PNP is very stable in the environment under normal conditions and is a highly toxic chemical that leads to bioaccumulation as well as cytotoxic/carcinogenic effects on living organisms [4,5]; due to all these reasons, the United States Environmental Protection Agency (USEPA) has considered PNP as a priority contaminant [6]. PNP is considered as the root cause of different problems such as irritation and inflammation in the eyes and nose, respiratory tract disorders, cardiac disorders, hematological problems, digestive problems, musculoskeletal issues, renal disease, and dermal/ocular problems in living organisms. It easily reacts with blood and leads to the formation of methemoglobin, which is mainly responsible for cyanosis confusion and unconsciousness [5,7]. Different environmental organizations such as the Brazilian Environmental Council, USEPA and European Commission have declared 100, 60 and $0.1 \mathrm{ppb}$ of PNP as maximum permitted limits [5,7], respectively. Therefore, the detection of PNP at trace levels is required.

Hence, it is the need of the hour to design a highly reliable and robust chemical sensor for the rapid detection of PNP. Several methods are reported in the literature for the effective and selective determination of PNP such as gas chromatography, high-performance liquid chromatography (HPLC), spectrophotometry, fluorescence, electrophoresis/capillary electrophoresis etc. [8-12]. However, expensive columns and a lot of reagents are required in HPLC and electrophoresis, aqueous samples cannot be used directly in gas chromatography, and interference is a major problem in spectrophotometric and fluorometric methods. In other words, all these techniques are either very expensive or time consuming or suffer from some other problems. Therefore, there is a need to develop a simple, cost-effective and quick technique that can effectively monitor the presence of PNP in a sample. Recently, several attempts have been made to synthesize a PNP sensor using various metal oxide nanomaterials such as copper oxide nanoparticles [13], a reduced graphene oxide/Au nanoparticle composite [14], a gold- $\mathrm{ZnO}-\mathrm{SiO}_{2}$ nanostructure [15], a $\mathrm{CeO}_{2} / \mathrm{ZnO}$ nano-composite [16], Ag doped $\mathrm{Nd}_{2} \mathrm{O}_{3}$ nanoparticles [17] and $\mathrm{CeO}_{2}-\mathrm{ZnO}$ nanoellipsoids [18].

Among the various transition metal oxides, zinc oxide is a very versatile, multifunctional semiconductor with a direct band gap of $3.37 \mathrm{eV}$. Zinc oxide is preferred over other metal oxide nanomaterials because it has a high exciton binding energy (60 meV), high catalytic efficiency, high-electron communication property, and cost-effective environmental sustainability [19-24]. Moreover, it has been observed that we can alter the properties of $\mathrm{ZnO}$ nanostructures for desired applications by manipulating the shape, grain size and morphology. However, the doping of $\mathrm{ZnO}$ nanostructures with transition metals, such as $\mathrm{Mn}, \mathrm{Ga}, \mathrm{Fe}, \mathrm{In}, \mathrm{Co}, \mathrm{Mg}, \mathrm{Al}, \mathrm{Sb}, \mathrm{Sn}, \mathrm{Ag}$, etc., has been found to deliver better control over the band gap [24-26]. Among the various transition metals, Ag ions have become the interest of many research groups [27,28], because of their suitable band gap, as they reduces the electron hole recombination and hence result in improvement in the photocatalytic properties, as well as proving to be an effective sensor material for toxic chemicals [29].

In this paper, we report the solution combustion synthesis of silver-doped zinc oxide nanostructures, $\mathrm{Ag}_{\mathrm{x}} \mathrm{Zn}_{1-\mathrm{x}} \mathrm{O}(\mathrm{x}=0,0.01,0.05$ and 0.10$)$. The solution combustion synthesis route was utilized in the present paper for the production of nanostructure materials in a single step, a time- and energy-saving process [30-32]. As-synthesized $\mathrm{Ag}_{\mathrm{x}} \mathrm{Zn}_{1-\mathrm{x}} \mathrm{O}$ nanostructures were utilized for the formation of a highly sensitive luminescence sensor for the detection of PNP in an aqueous medium. The limit of detection (LOD) for PNP was calculated for $\mathrm{ZnO}$ as well as Ag-doped $\mathrm{ZnO}$ samples, by using the Stern-Volmer equation. 


\section{Experimental}

\subsection{Materials}

Zinc nitrate hexahydrate $\left(\mathrm{Zn}\left(\mathrm{NO}_{3}\right)_{2} \cdot 6 \mathrm{H}_{2} \mathrm{O}\right)$, tartaric acid $\left(\mathrm{C}_{4} \mathrm{H}_{6} \mathrm{O}_{6}\right)$, silver nitrate $\left(\mathrm{AgNO}_{3}\right)$ and p-nitrophenol $\left(\mathrm{C}_{6} \mathrm{H}_{5} \mathrm{NO}_{3}\right)(\mathrm{PNP})$ were all of analytical grade and obtained from Merck, Germany and these chemicals were directly used as received without further purification. Deionized (DI) water obtained from a Millipore Elix system was used for all the experiments.

\subsection{Synthesis of $\mathrm{ZnO}$ Nanoparticles}

Pure $\mathrm{ZnO}$ nanostructures were synthesized from zinc nitrate hexahydrate (oxidizer) and tartaric acid (fuel) using a typical reaction procedure of solution combustion by optimizing the stoichiometric ratio $(\phi=1)$. In the synthesis process, $4.0 \mathrm{~g}$ of $\mathrm{Zn}\left(\mathrm{NO}_{3}\right)_{2} \cdot 6 \mathrm{H}_{2} \mathrm{O}$ and $2.0 \mathrm{~g}$ of $\mathrm{C}_{4} \mathrm{H}_{6} \mathrm{O}_{6}$ were dissolved in $50 \mathrm{~mL}$ of deionized water, separately. Then, the tartaric acid solution was added drop-wise to the $\mathrm{Zn}\left(\mathrm{NO}_{3}\right)_{2} \cdot 6 \mathrm{H}_{2} \mathrm{O}$ solution with continuous stirring at room temperature. The resultant solution was thoroughly stirred at room temperature for $30 \mathrm{~min}$, and the resulting solution was heated till the evaporation of the excess water content to obtain the gel-like materials. The resulting gel-like material was transferred into a muffle furnace in a silicate crucible at $500{ }^{\circ} \mathrm{C}$ for $1 \mathrm{~h}$. In the muffle furnace, tartaric acid (fuel) and zinc nitrate hexahydrate (oxidizer) were combusted for the formation of the crystalline $\mathrm{ZnO}$ nanostructures, at high temperature. The synthesized nanostructures were further washed with distilled water followed by ethanol, and finally, the precipitates were dried in an oven at $60^{\circ} \mathrm{C}$.

\subsection{Synthesis of $A g$-Doped $\mathrm{ZnO}$ Nanostructures}

The same procedure was adopted for the synthesis of Ag-doped $\mathrm{ZnO}$ by taking an appropriate amount of $\mathrm{AgNO}_{3}$. For the synthesis of $1 \%, 5 \%$ and $10 \%$ Ag-doped $\mathrm{ZnO}, 0.022,0.114$ and $0.228 \mathrm{~g}$ of $\mathrm{AgNO}_{3}$ dissolved in $50 \mathrm{~mL}$ of water was added, respectively; after that, the same procedure was adopted as in Section 2.2.

\subsection{Characterization}

The synthesis of the nanostructures was confirmed by characterizing them for their morphological, structural and optical properties. The morphological investigation was carried out by using field emission scanning electron microscopy (SEM) with a FEI Quanta 200 FEG (Pittsburgh, PA, USA) with the energy dispersive X-ray spectrometer Bruker XFlash 4030 (EDS), while the structural characterization was performed using X-ray diffractometer (D8 Discover, Bruker AXS, Karlsruhe, Germany). The optical properties of the as-synthesized nanostructures were examined at room temperature by using UV-visible spectroscopy (AvaSpec-2048). The XPS study of the ZnO powder and Ag-doped $\mathrm{ZnO}$ powder was carried out by employing $\mathrm{X}$-ray energy dispersion spectrometer (Bruker XFlash 4030, Karlsruhe, Germany). The sensing properties of the pure ZnO and Ag-doped ZnO nanostructures were recorded using room-temperature photoluminescence spectra (Perkin Elmer-LS55 fluorescence spectrophotometer, Waltham, MA, USA).

\subsection{Luminescent Sensor Evaluation of $\mathrm{ZnO}$ and $\mathrm{Ag}$ - $\mathrm{ZnO}$ Nanoparticles}

The Perkin Elmer LS55 fluorescence spectrophotometer was used at room temperature to determine the sensing properties of the pure $\mathrm{ZnO}$ and $\mathrm{Ag}-\mathrm{ZnO}$ nanostructure. In this investigation, the pure $\mathrm{ZnO}$ and $\mathrm{Ag}-\mathrm{ZnO}$ nanostructures were utilized to fabricate the luminescent sensor interface for the sensing of PNP. The obtained $\mathrm{ZnO}$ and $\mathrm{Ag}-\mathrm{ZnO}$ nanostructures were dispersed in DI water $(1.5 \mathrm{mg}$ in $50 \mathrm{~mL}$ of $\mathrm{H}_{2} \mathrm{O}$ ), and a $5 \mathrm{mM}$ stock solution of PNP was also prepared for the entire experiment. All the solutions were prepared $30 \mathrm{~min}$ before performing the experiments. The sensing experiments were performed at different concentrations of PNP in the range of $0.833-9.980 \mu \mathrm{M}$. 


\section{Results and Discussion}

\subsection{FESEM of $A g_{x} \mathrm{Zn}_{1-x} \mathrm{O}$ Nanostructure}

The surface morphology and variation in the particle size were studied by using high-resolution FESEM. Typical low and high magnification FESEM images of the pure $\mathrm{ZnO}, 1 \% \mathrm{Ag}-\mathrm{ZnO}, 5 \% \mathrm{Ag}-\mathrm{ZnO}$ and $10 \% \mathrm{Ag}-\mathrm{ZnO}$ nanostructures are shown in Figure $1 \mathrm{a}-\mathrm{h}$. A careful observation of Figure 1 reveals that the as-synthesized nanostructures were uniformly grown at very high density. It was also observed that the structure of $\mathrm{ZnO}$ did not show any deviation with the doping of silver ions and remained uniform even at a high concentration of silver ions (10\% Ag ions).
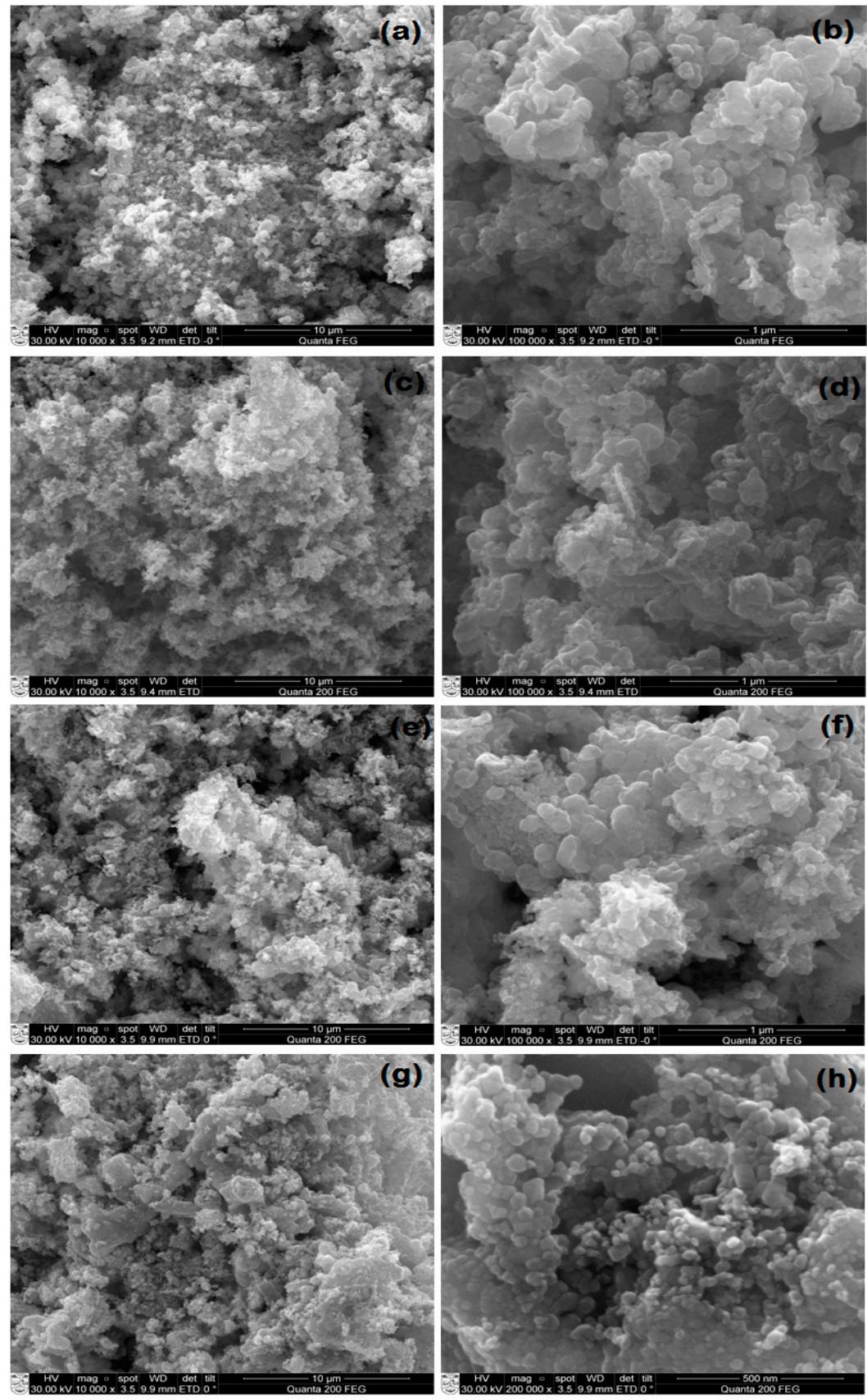

Figure 1. Low and high-magnification FESEM micrographs of pure $\mathrm{ZnO}(\mathbf{a}, \mathbf{b})$ and $1 \%(\mathbf{c}, \mathbf{d}), 5 \%(\mathbf{e}, \mathbf{f})$ and $10 \%$ (g,h) Ag-doped $\mathrm{ZnO}$ nanostructures. 


\subsection{PXRD}

Figure 2a represents the $\mathrm{XRD}$ spectra of the pure $\mathrm{ZnO}$ and $\mathrm{Ag}$ - $\mathrm{ZnO}$ nanostructures, which were recorded in the range of $20-80^{\circ}$. The $\mathrm{XRD}$ spectra show that pure $\mathrm{ZnO}$ has characteristic diffraction peaks attributed to the crystalline nature of $\mathrm{ZnO}$. A clear peak of silver ions was also observed for the $\mathrm{Ag}-\mathrm{ZnO}$ composite, confirming the doping of $\mathrm{Ag}$ into $\mathrm{ZnO}$. The intensity of the peak also revealed that there is a slight intensity increase with an increasing concentration of silver ions.

The data were found to be in reasonable agreement with the Joint Committee on Powder Diffraction Standards (JCPDS) card for ZnO (JCPDS 036-1451) [33]. In Figure 2a, the strongest dhk1 values resemble the $2 \theta$ values of $31.74^{\circ}, 34.42^{\circ}, 36.26^{\circ}, 47.66^{\circ}, 56.70^{\circ}, 63.07^{\circ}, 66.42^{\circ}, 67.92^{\circ}, 69.10^{\circ}$, $72.45^{\circ}$ and $77.31^{\circ}$ for (100), (002), (101), (102), (110), (103), (200), (112), (201), (004) and (202), respectively, which confirms the presence of the wurtzite hexagonal phase of $\mathrm{ZnO}$. However, in the silver-doped zinc oxide sample, in addition to the $\mathrm{ZnO}$ reflections, the characteristic peaks (111), (200) and (220) corresponding to $\mathrm{Ag}$ ions appeared at $2 \theta$ of $38.29^{\circ}, 44.28^{\circ}$ and $62.93^{\circ}$, respectively. From Figure $2 \mathrm{a}$, it can be observed that as the concentration of Ag increases, the intensity of the Ag ion peaks becomes more predominant. The XRD spectra clearly indicate that only $\mathrm{ZnO}$ and $\mathrm{Ag}$ ions are present; no other peak is found corresponding to any other impurity atom such as $\mathrm{Zn}$ and $\mathrm{Ag}_{2} \mathrm{O}$. This simply reveals that the as-synthesized nanostructures are crystalline and pure up to the detection limit of XRD.

Furthermore, a close comparison of the peaks (100), (002) and (101) is shown in Figure 2b, which clearly reveals that up to the studied concentration of silver ions $(10 \% \mathrm{Ag})$, no deformation in the structure is observed. The crystallite size was calculated using the XRD peak with the Debye-Scherrer formula, which is given as:

$$
D=\frac{k \lambda}{\beta \operatorname{Cos} \theta}
$$

where $k$ is the structural constant, $\lambda$ is the wavelength of the $X$-ray, $D$ is the size of the nanoparticle and $\beta$ is the full width at half maximum. Using Equation (1), the crystallite particle sizes were determined to be 39, 32, 26 and $21 \mathrm{~nm}$, respectively, for the pure $\mathrm{ZnO}$ and $1 \%, 5 \%$ and $10 \%$ Ag-doped $\mathrm{ZnO}$ nanostructures.

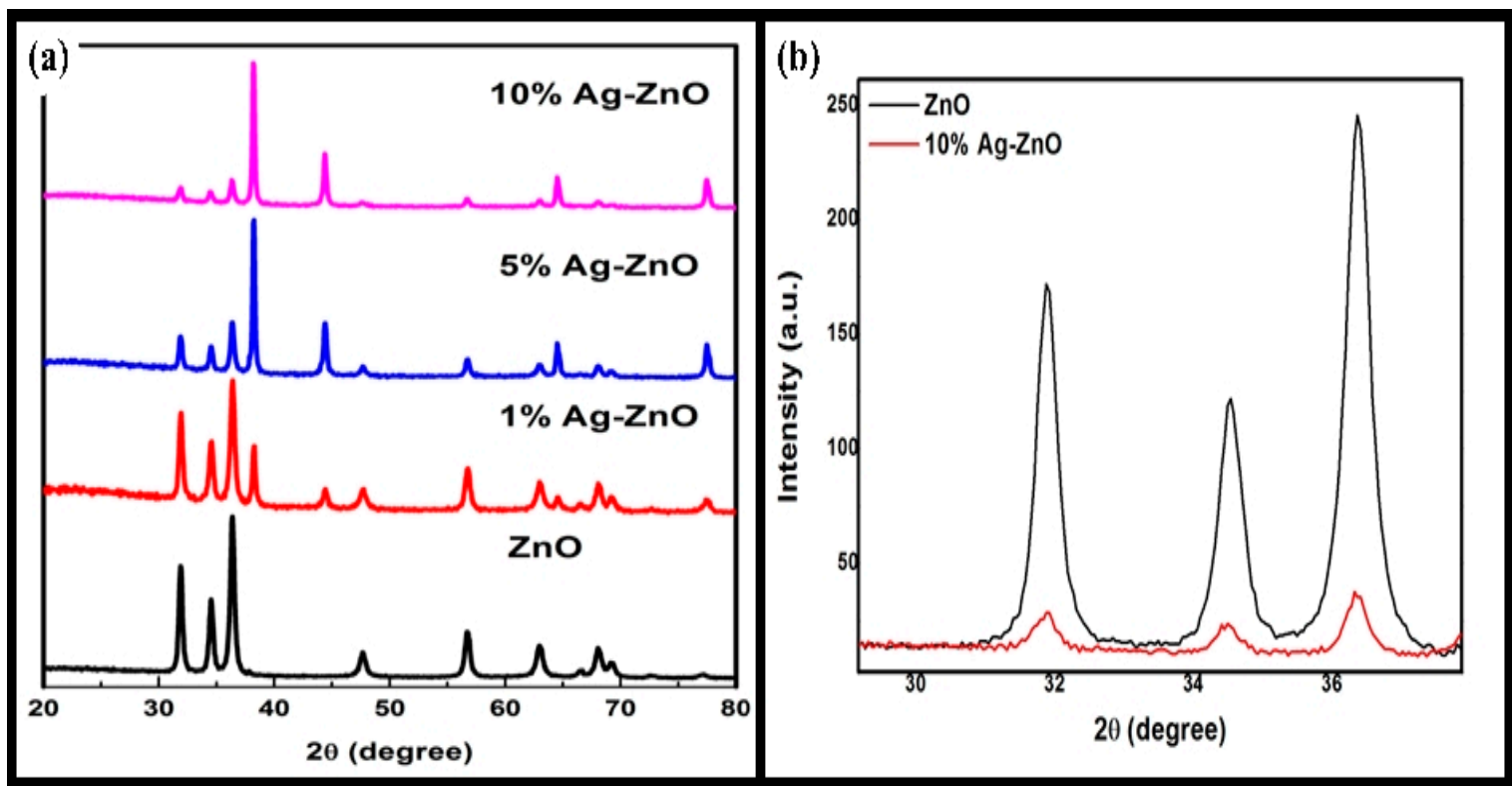

Figure 2. (a) XRD pattern of $A g_{x} \mathrm{Zn}_{1-\mathrm{x}} \mathrm{O}$ nanostructure and (b) comparison of (100), (002) and (101) peaks from the XRD pattern of pure $\mathrm{ZnO}$ and $10 \% \mathrm{Ag}-\mathrm{ZnO}$ nanostructures. 


\subsection{EDS}

The composition and purity of the as-synthesized $\mathrm{ZnO}$ and $\mathrm{Ag}-\mathrm{ZnO}$ nanostructures were investigated by using EDS. The EDS data are provided as supplementary data (Figures S1-S4), which confirmed that the nanoparticles were made of zinc, oxygen and silver atoms only.

\subsection{UV-Visible}

The optical properties of the $\mathrm{Ag}_{\mathrm{x}} \mathrm{Zn}_{1-\mathrm{x}} \mathrm{O}(\mathrm{x}=0,0.01,0.05$ and 0.10$)$ nanostructures were studied by using UV-visible (UV-Vis) spectroscopy. The results indicate that the maximum absorption peaks are at 375, 379, 382 and $385 \mathrm{~nm}$ (Figure 3) for the pure $\mathrm{ZnO}, 1 \% \mathrm{Ag}-\mathrm{ZnO}, 5 \% \mathrm{Ag}-\mathrm{ZnO}$ and $10 \% \mathrm{Ag}-\mathrm{ZnO}$ nanostructures, respectively, corresponding to wurtzite hexagonal phase bulk $\mathrm{ZnO}$ [29]. The red shift due to the presence of Ag ions observed in the absorption maxima is attributed to the decrease in the band gap energy with an increase in the concentration of Ag ions. No other absorption peak was detected corresponding to impurities, which confirms that the synthesized $\mathrm{Ag} / \mathrm{ZnO}$ nanostructures possess good optical properties.

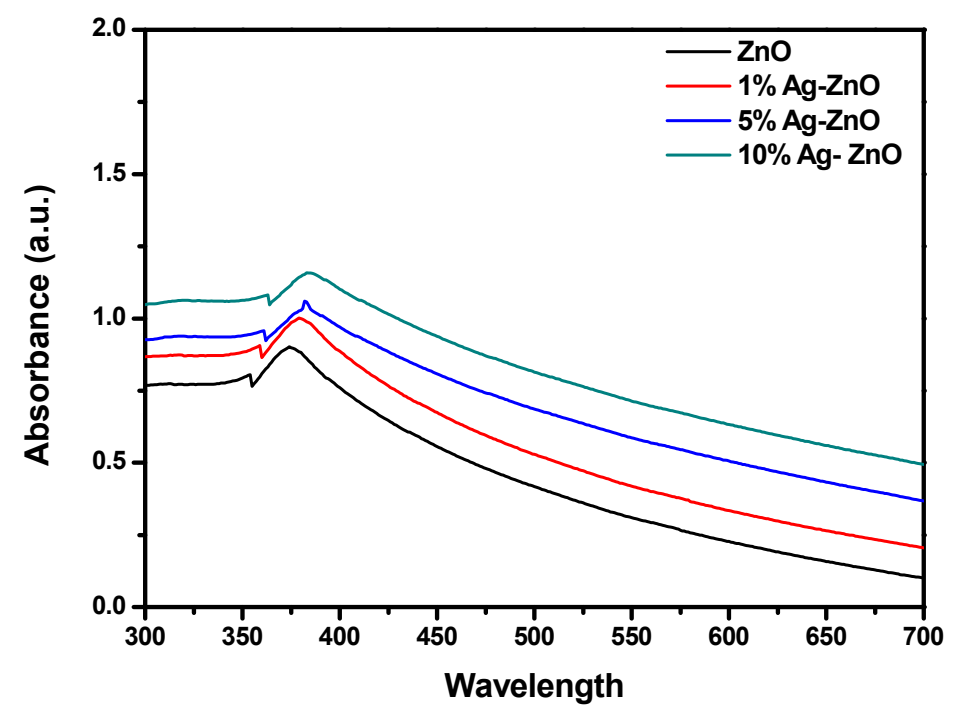

Figure 3. UV-Vis spectrum of pure $\mathrm{ZnO}, 1 \% \mathrm{Ag}-\mathrm{ZnO}, 5 \% \mathrm{Ag}-\mathrm{ZnO}$ and $10 \% \mathrm{Ag}-\mathrm{ZnO}$ nanostructures.

\subsection{XPS}

The XPS survey spectra for the $\mathrm{ZnO}$ and Ag-doped $\mathrm{ZnO}$ samples are presented in Figure 4. From the spectra, one can see that the main elements on the surface of the samples are zinc, oxygen, carbon and silver. It can be noted that the silver $\mathrm{Ag} 3 \mathrm{~d}$ peak appears only for the Ag-doped $\mathrm{ZnO}$ samples. A low-intensity carbon C 1 s peak at $285 \mathrm{eV}$ is present, most likely due to atmospheric contaminants adsorbed on the surface of the sample. High-resolution spectra were acquired in the $\mathrm{O} 1 \mathrm{~s}, \mathrm{Zn} 2 \mathrm{p}$ and Ag $3 \mathrm{~d}$ regions for obtaining the atomic concentrations (Table 1) and possible chemical bond identification. The data in Table 1 were determined by calculating the appropriate peak area after Shirley background subtraction. The zinc high-resolution XPS spectra in the Zn 2p region (Figure 5) for the $\mathrm{ZnO}$ and Ag-doped $\mathrm{ZnO}$ samples show two peaks due to spin-orbit splitting: $\mathrm{Zn} 2 \mathrm{p}_{3 / 2}$ and $\mathrm{Zn}$ $2 \mathrm{p}_{1 / 2}$. The position of the $\mathrm{Zn} 2 \mathrm{p}_{3 / 2}$ peak at approximately $1021.7 \mathrm{eV}$ is assigned to the $\mathrm{ZnO}$ bond since it is in good agreement with the known peak values and shape for $\mathrm{ZnO}(1021.7 \mathrm{eV})[34,35]$. 


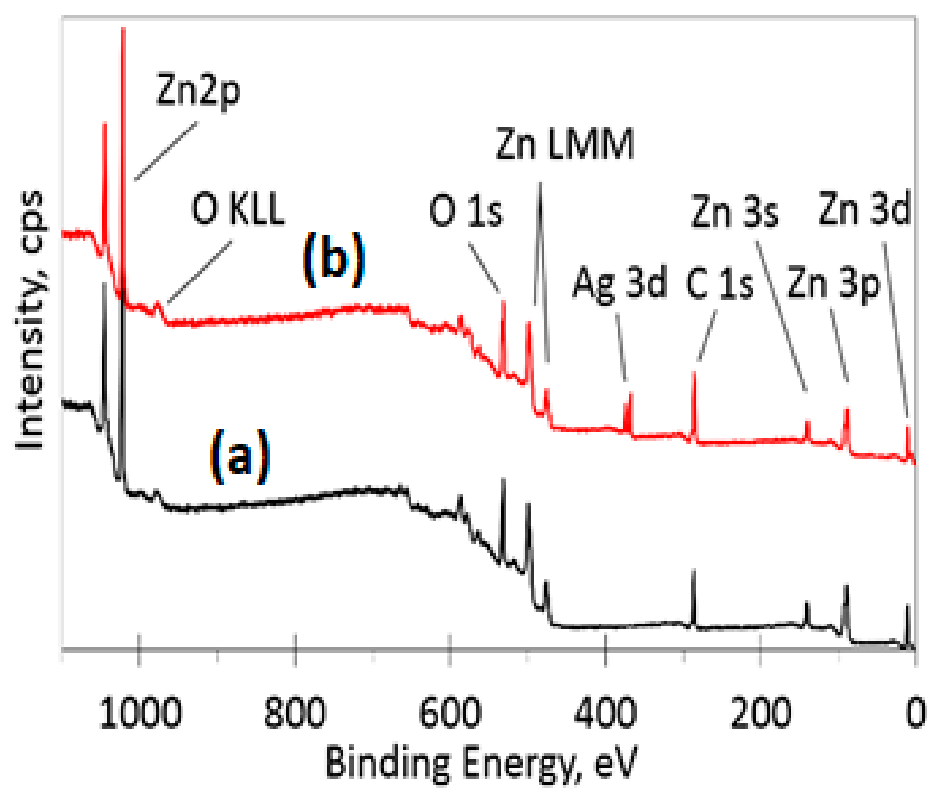

Figure 4. XPS survey spectra of (a) ZnO and (b) 10\% Ag-ZnO powder samples.

Table 1. Atomic concentrations calculated from the XPS measurements.

\begin{tabular}{ccccc}
\hline \multirow{2}{*}{ Element } & \multicolumn{5}{c}{ Atomic Concentrations (\%) } \\
\cline { 2 - 5 } & $\mathbf{Z n O}$ & $\mathbf{1 \%} \mathbf{A g - Z n O}$ & $\mathbf{5 \%} \mathbf{A g - Z n O}$ & $\mathbf{1 0 \%} \mathbf{A g - Z n O}$ \\
\hline Zn 2p & 17.06 & 13.7 & 23.7 & 12.56 \\
\hline $\mathrm{O} 1 \mathrm{~s}$ & 28.09 & 26.35 & 31.01 & 26.04 \\
\hline $\mathrm{C} \mathrm{1s}$ & 54.85 & 59.62 & 43.49 & 59.35 \\
\hline Ag 3d & 0 & 0.33 & 1.8 & 2.05 \\
\hline
\end{tabular}

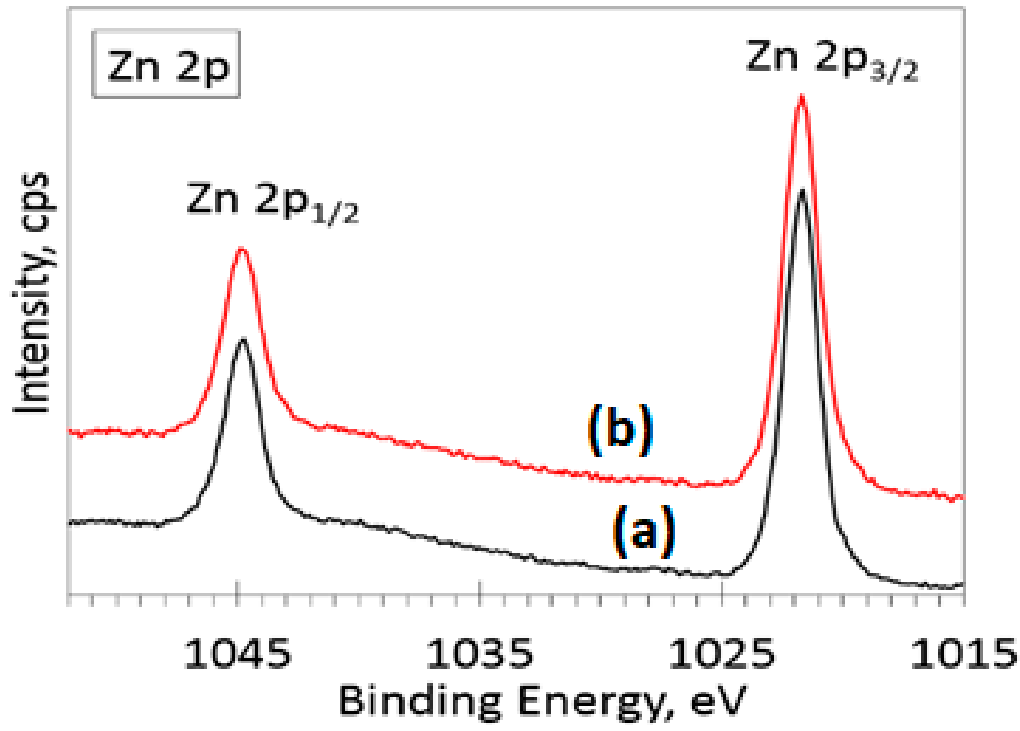

Figure 5. High-resolution XPS spectra in Zn 2p region for (a) ZnO and (b) 10\% Ag-ZnO powder samples.

The deconvolution of the $\mathrm{O} 1 \mathrm{~s}$ spectra (Figure $6 \mathrm{~b}$ ) showed a negligible shift (less than $0.1 \mathrm{eV}$ ) of the main peak $(\mathrm{ZnO})$ position $(530.4 \mathrm{eV})$ due to the incorporation of $10 \% \mathrm{Ag}$. The main difference between the two spectra is in the left side of the spectra. Namely, the peaks at $531.8 \mathrm{eV}$ (oxygen-deficient regions within the matrix of $\mathrm{ZnO}$, green curve) and $532.5 \mathrm{eV}$ (C-O bonds and chemisorbed atmospheric oxygen 
species, blue curve) are more intense for the $10 \%$ Ag sample. This variation of intensity could arise due to different amounts of adsorbed atmospheric contaminants on the sample surface. The highest binding energy peak at $532.5 \mathrm{eV}$ is usually assigned to $\mathrm{C}-\mathrm{O}$ bonds and chemisorbed atmospheric oxygen species [34-36]. Both peaks (531.8 and $532.5 \mathrm{eV}$ ) are more intense for the $10 \%$ Ag-doped sample (Figure 6b). This increase in intensity could arise due to different amounts of adsorbed atmospheric contaminants on the sample surface. The lower intensity peak positioned at $531.8 \mathrm{eV}$ corresponds to the known values of binding energy for $\mathrm{O}^{2-}$ ions in oxygen-deficient regions within the matrix of $\mathrm{ZnO}$ [37] or $\mathrm{O}-\mathrm{C}=\mathrm{O} / \mathrm{C}=\mathrm{O}$ species bonds from adsorbed atmospheric contaminants [38]. In the $\mathrm{Ag} 3 \mathrm{~d}$ spectra (Figure 7), two peaks were detected, fitted using a sum of Lorentzian-Gaussian (80:20) functions, with an asymmetric peak shape at positions 386.2 and $374.2 \mathrm{eV}$ on the binding energy scale. The deconvoluted Ag $3 \mathrm{~d}$ spectra for the $1 \% \mathrm{Ag}-\mathrm{ZnO}$ powder sample is shown in the supplementary data (Figure S5). These peak positions are in good agreement with the well-known spin-orbit split energy values [39] of $\mathrm{Ag} 3 \mathrm{~d}_{5 / 2}$ and $\mathrm{Ag} 3 \mathrm{~d}_{3 / 2}$ doublet peaks for $\mathrm{Ag}^{0}$. The position and shape of these peaks indicate the presence of metallic silver in Ag-doped $\mathrm{ZnO}$ powder samples.

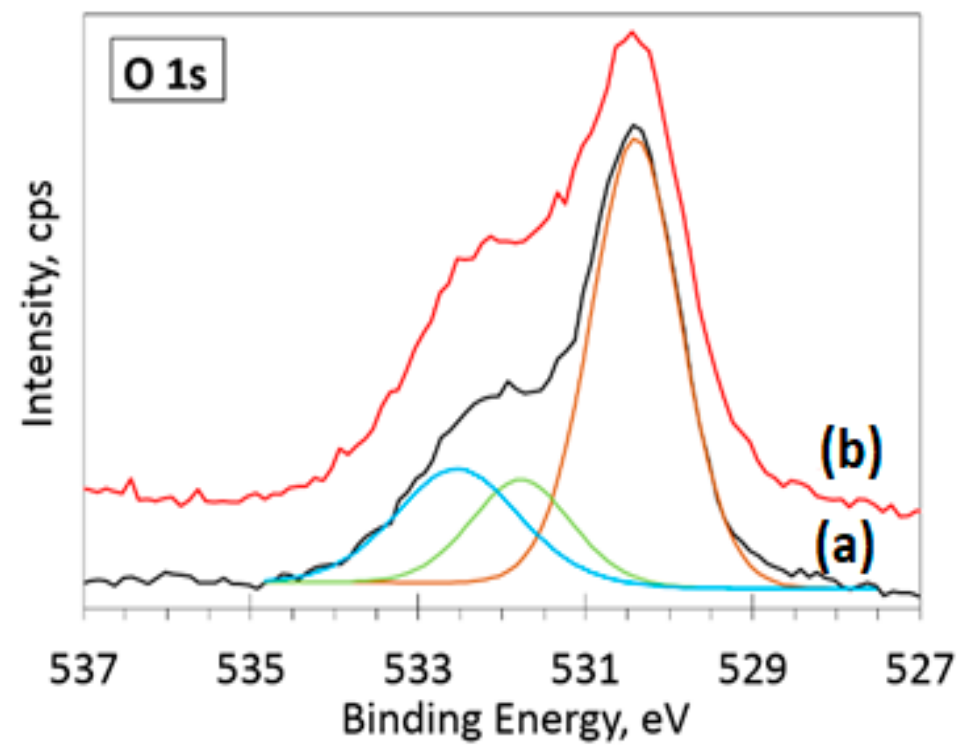

Figure 6. Deconvoluted high-resolution XPS spectra in O 1s region for (a) $\mathrm{ZnO}$ and (b) $10 \% \mathrm{Ag}-\mathrm{ZnO}$ powder samples.

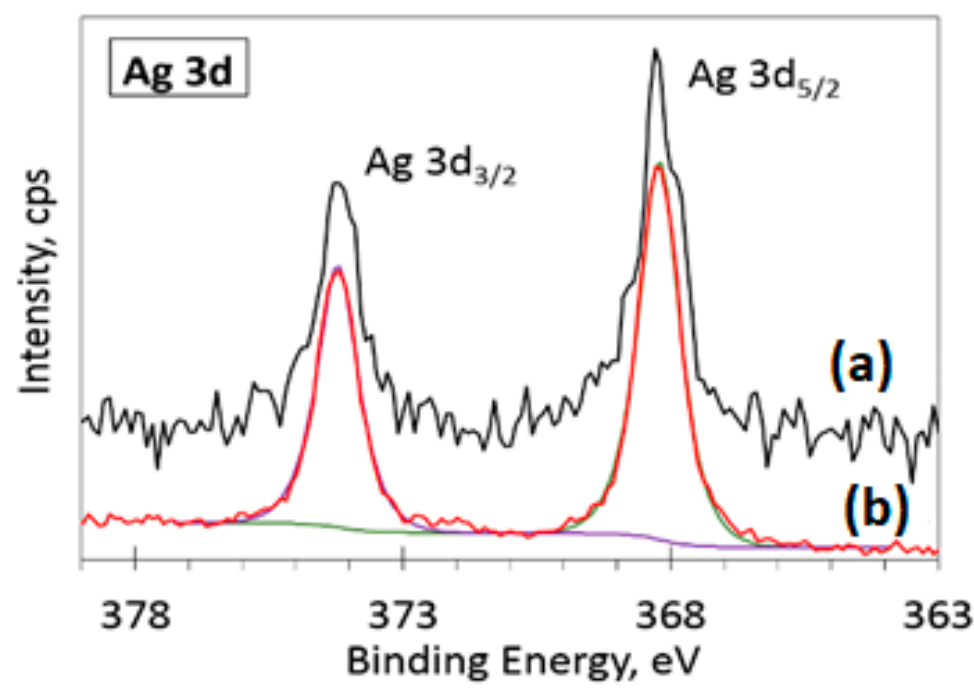

Figure 7. High-resolution XPS spectra for (a) $1 \% \mathrm{Ag}-\mathrm{ZnO}$ powder sample and (b) deconvoluted spectra for $10 \%$ sample. 


\subsection{Ag-ZnO Nanoparticles as Fluorescent Sensor for p-Nitrophenol}

The stability of the synthesized Ag-doped $\mathrm{ZnO}$ nanostructures was studied by using a fluorescence spectrophotometer, and there was no change in the intensity and position of the peak, even after a time of 15 days. The reproducibility values of the fluorescence measurements were estimated to be $\pm 0.1 \%$. The as-synthesized $\mathrm{Ag}_{\mathrm{x}} \mathrm{Zn}_{1-\mathrm{x}} \mathrm{O}(\mathrm{x}=0,0.01,0.05$ and 0.10$)$ samples were studied for the fluorescence sensing of p-nitrophenol (PNP). Before conducting the sensing experiments, photoluminescence (PL) spectra of pure $\mathrm{ZnO}$ and $\mathrm{Ag}$-doped $\mathrm{ZnO}$ nanostructures were recorded at various excitation wavelengths in the range $330-410 \mathrm{~nm}$ with a regular gap of $10 \mathrm{~nm}$ in order to find out the excitation maxima for the nanostructures. In the PNP concentration-dependent studies, the concentration of PNP was changed gradually, while the concentrations of the nanostructures were kept constant $(1.5 \mathrm{mg}$ in $50 \mathrm{~mL}$ ). The response of the PL quenching for $\mathrm{ZnO}$ and $\mathrm{Ag}$-doped $\mathrm{ZnO}$ is illustrated in Figure 8.
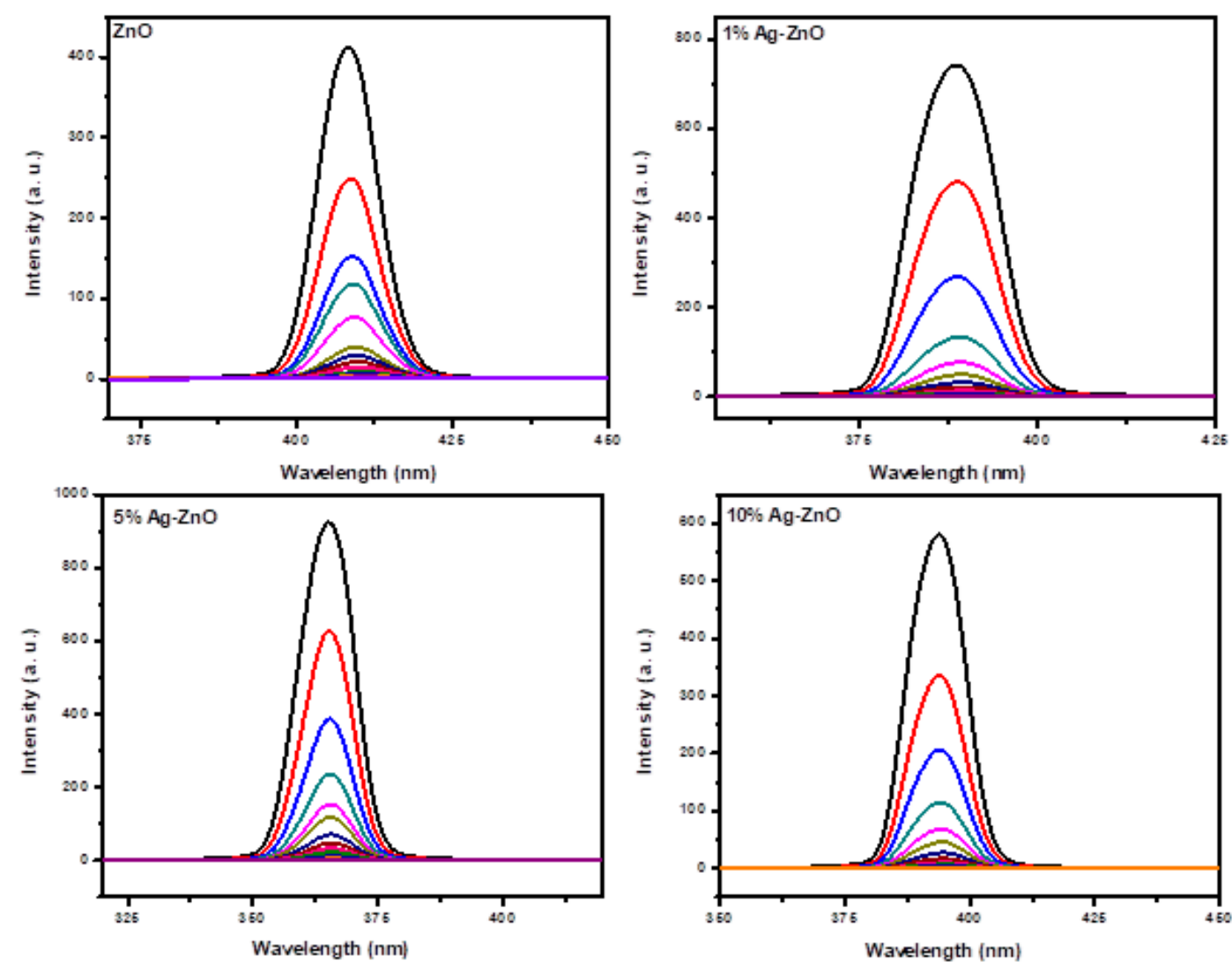

Figure 8. It was observed that the photoluminescence (PL) intensity of the pure $\mathrm{ZnO}$ and Ag-doped $\mathrm{ZnO}$ nanostructures decreases with an increase in the concentration of p-nitrophenol (PNP), which clearly indicates the binding of PNP to the surface of nanostructures.

The Stern and Volmer equation [40] initially deal with the kinetics analysis of fluorescence quenching, which has promising applications for investigating bimolecular interactions in the electronic excited state. The analysis of the fluorescence quenching processes was performed by using the Stern-Volmer equation [40]:

$$
\frac{I_{0}}{I}=K_{s v}[Q]+1
$$

where $I_{o}$ is the intensity before and after the addition of PNP, while $I$ correspond to the intensity after the addition of PNP. $K_{s v}$ and $[Q]$ are the Stern-Volmer quenching constant and the concentration of the quencher, respectively. Figure 9 shows the variation of $\left(I_{o /} I\right)-1$ vs. The concentration of the PNP quencher. In pure $\mathrm{ZnO}$ as well as $\mathrm{Ag}$-doped $\mathrm{ZnO}$, it was observed that the Stern-Volmer plots show exponential behavior (linear as well as non-linear) over the entire concentration range of PNP studied. 
Linear behavior was observed upon increasing the concentration up to a certain level, implying the dominance of the static quenching over the dynamic quenching process; however, a further increase in concentration resulted in an exponential increase, which suggests that there exist both types of quenching, i.e., a combination of static and dynamic quenching by the same quencher [40].
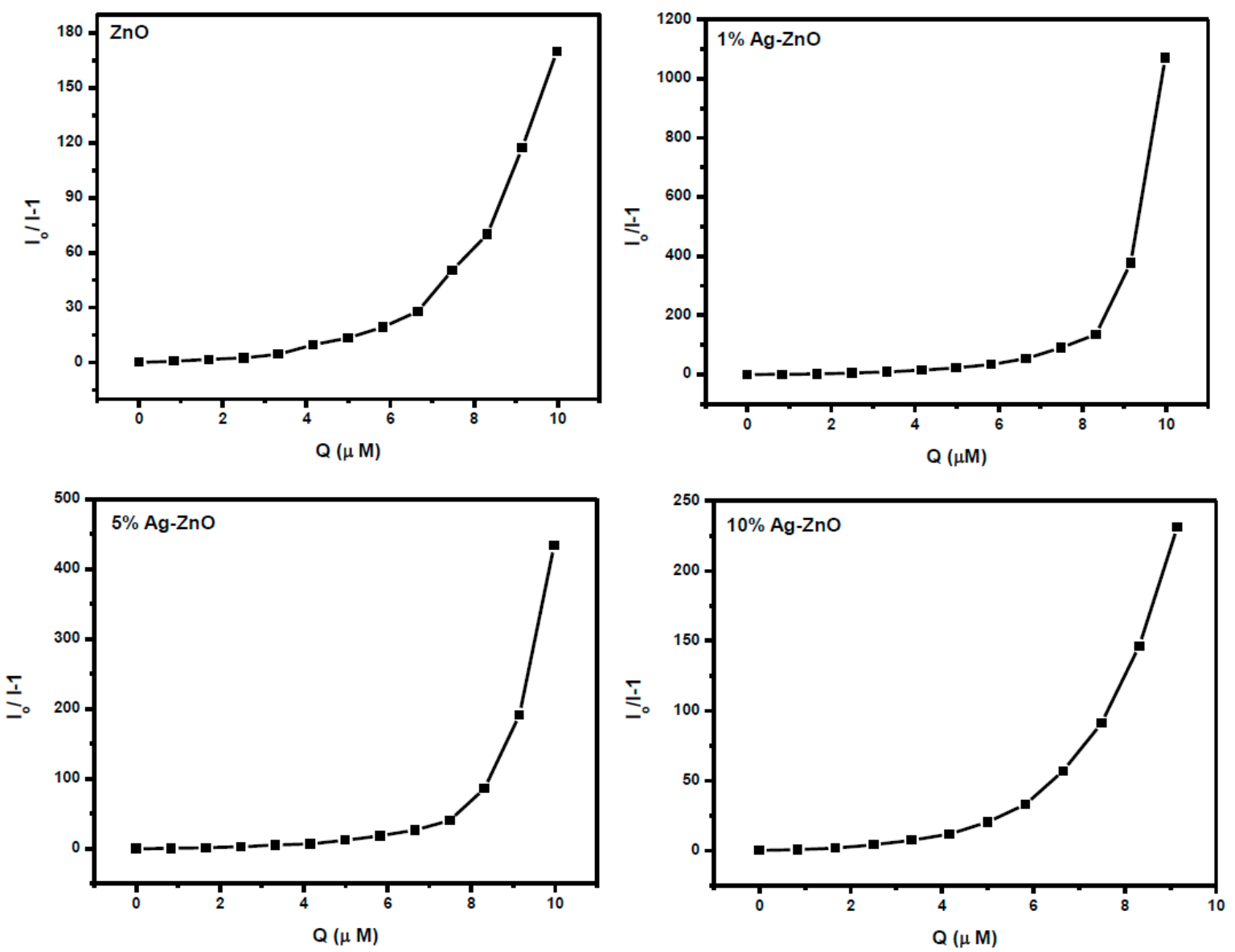

Figure 9. Stern-Volmer plots of $\mathrm{Ag}_{\mathrm{x}} \mathrm{Zn}_{1-\mathrm{x}} \mathrm{O}$ nanostructure with increasing concentration of p-nitrophenol.

To resolve this ambiguity, on account of the non-linear response of the intensity ratio to the concentration of the analyte, a modified Stern-Volmer equation has been suggested [37,41]:

$$
\frac{I_{0}}{I}=K_{s v}[Q] e^{V[Q]}+1
$$

Equation (3) can further be simplified as follows:

$$
\frac{I_{0}-I}{I e^{V[Q]}}=K_{s v}[Q]
$$

where $V$ is the static quenching constant and is obtained from Equation (4) by plotting $\frac{I_{o}-I}{I e^{V[Q]}}$ vs. [Q] and by varying $V$ till a linear response is obtained as shown in Figure.

Figure $10 \mathrm{a}-\mathrm{d}$ show a linear fit of the plot $\frac{I_{0}-I}{e^{V[Q]}}$ versus PNP concentration, with regression coefficients of $0.952,0.963,0.975$ and 0.994 for the pure $\mathrm{ZnO}$ and $1 \%, 5 \%$ and $10 \%$ Ag-doped $\mathrm{ZnO}$ nanostructures, respectively. The value of $V$ fits to 0.31 with a $K_{S V}$ of $7.33 \times 10^{5} \mathrm{M}^{-1}$ in the case of pure $\mathrm{ZnO}$, while $V$ fits to $0.30,0.25$ and 0.42 with $K_{S V}$ of $1.31 \times 10^{6}, 8.093 \times 10^{5}$ and $5.24 \times 10^{5} \mathrm{M}^{-1}$ for the $1 \%, 5 \%$ and $10 \%$ Ag-doped $\mathrm{ZnO}$ nanostructures, respectively. The limits of detection (LODs), calculated following the $3 \sigma$ IUPAC criteria, were found to be $2.17,1.60,1.18$ and $0.66 \mu \mathrm{M}$ for the pure 
$\mathrm{ZnO}$ and $1 \%, 5 \%$ and $10 \% \mathrm{Ag}$-doped $\mathrm{ZnO}$ nanostructures, respectively, which clearly indicates that the presence of Ag improved the LOD for a luminescent sensor for PNP. The sensing mechanism has been shown in Scheme 1. The PL quenching of Ag-doped ZnO can be attributed to the analytes binding on the surface of nanostructure, which traps the excited electron-by-electron transfer mechanism [42]. The LOD for PNP calculated for various samples of $\mathrm{ZnO}$ as well as Ag-doped $\mathrm{ZnO}$ is also compared with the literature (Table 2).

Table 2. Comparison of limits of detection (LODs) between synthesized Ag-ZnO nanostructures and various reported chemical sensors for PNP.

\begin{tabular}{cccc}
\hline Material & LOD $(\mu \mathbf{M})$ & Technique & Ref. \\
\hline $\mathrm{CeO}_{2} / \mathrm{ZnO}$ & 3.05 & Photoluminescence & {$[16]$} \\
\hline Nano gold/glassy carbon electrode & 8.0 & Amperometric & {$[43]$} \\
\hline $\mathrm{NiO} / \mathrm{CeO}_{2}$ nanocomposite & 2.48 & Amperometric & {$[44]$} \\
\hline $\mathrm{GO} /$ screen printed electrode & 0.9918 & Amperometric & {$[45]$} \\
\hline Manganese oxide nanoparticles & 15.65 & Amperometric & {$[46]$} \\
\hline Zinc oxide & 2.17 & Luminescence & Present Work \\
\hline $1 \% \mathrm{Ag}-\mathrm{ZnO}$ & 1.60 & Luminescence & Present Work \\
\hline $5 \% \mathrm{Ag}-\mathrm{ZnO}$ & 1.18 & Luminescence & Present Work \\
\hline $10 \% \mathrm{Ag}-\mathrm{ZnO}$ & 0.66 & Luminescence & Present Work \\
\hline
\end{tabular}
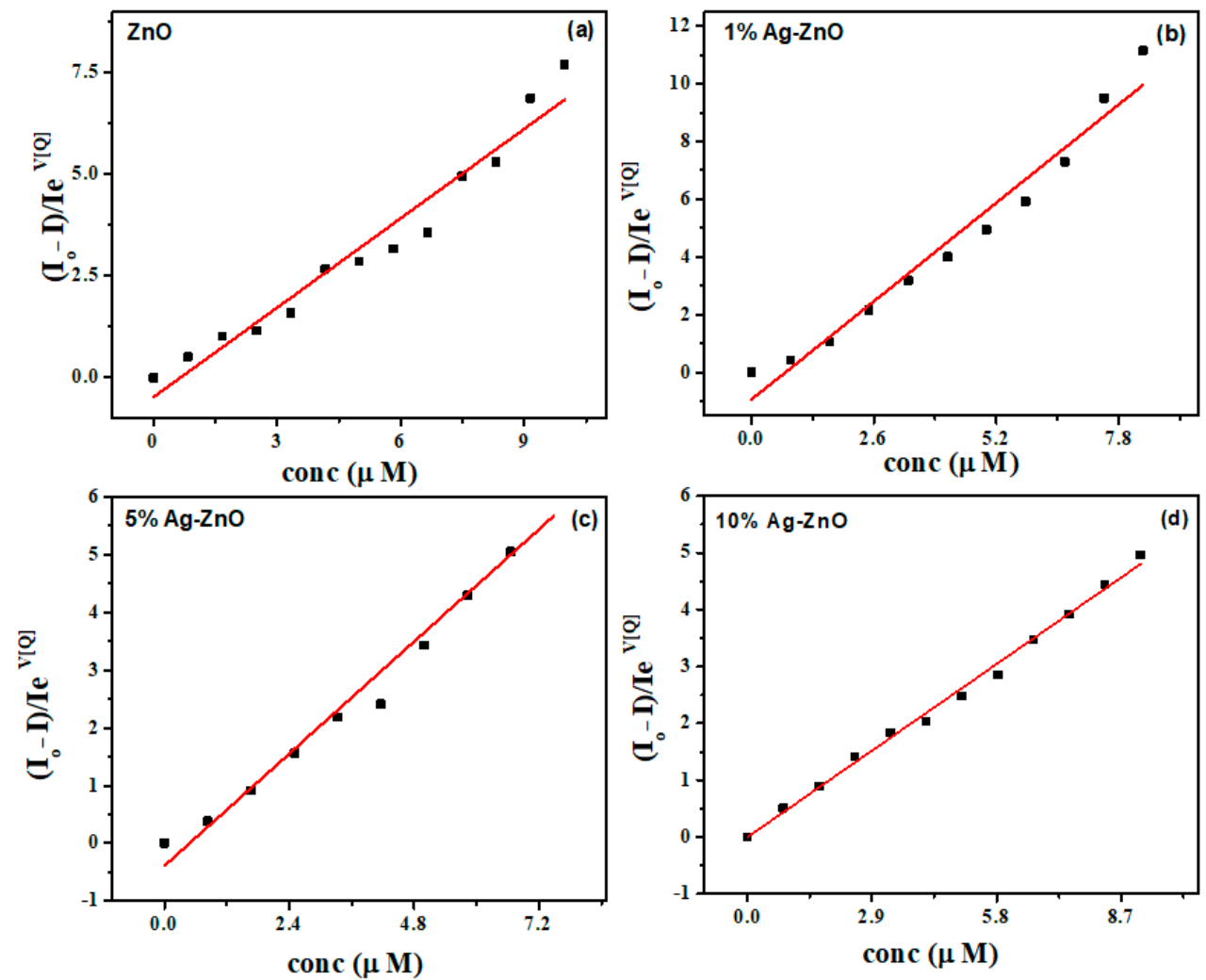

Figure 10. Modified Stern-Volmer plots of (a) ZnO, (b) 1\% Ag-ZnO, (c) 5\% Ag-ZnO and (d) 10\% Ag doped $\mathrm{ZnO}$ nanostructures. 


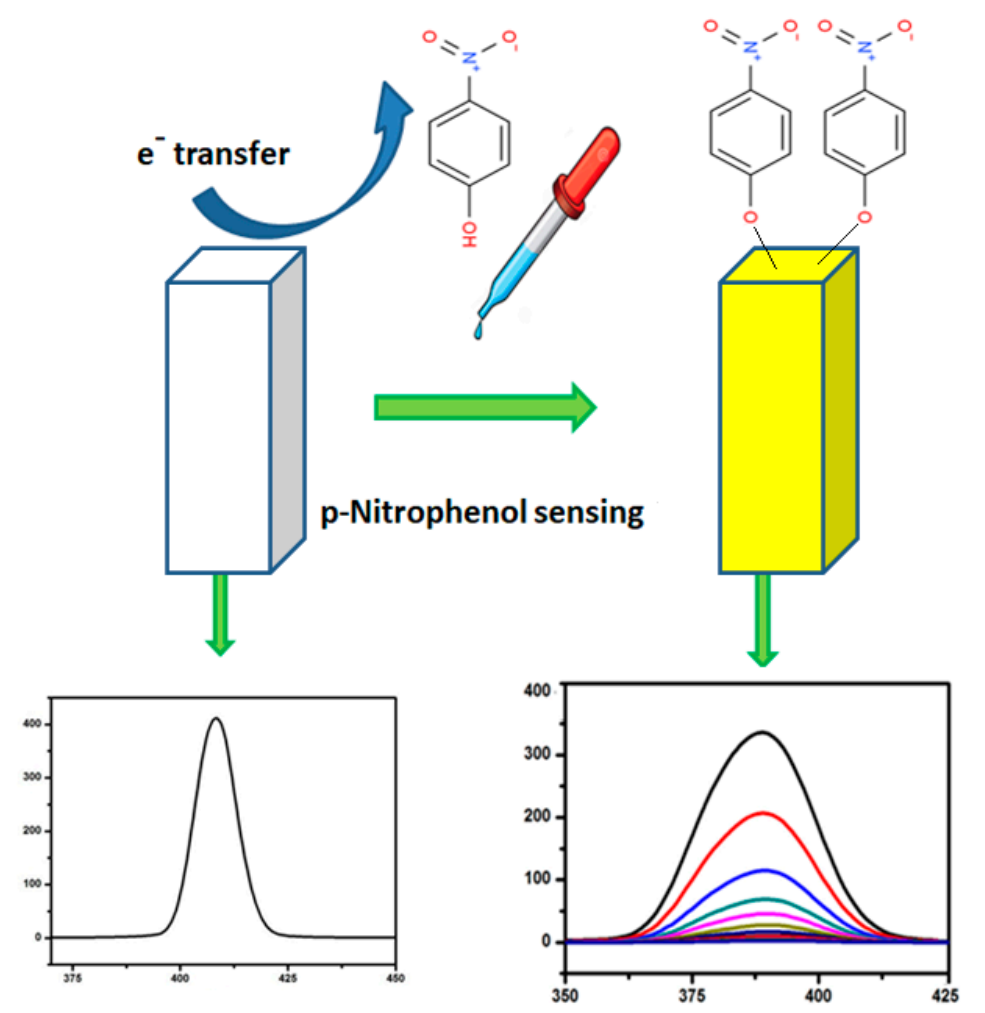

Scheme 1. Proposed mechanism for the photoluminescence sensing of PNP.

\section{Conclusions}

In summary, we successfully synthesized $\mathrm{ZnO}$ and $\mathrm{Ag}$-doped $\mathrm{ZnO}$ nanostructures via a solution combustion process. The synthesized $\mathrm{ZnO}$ and $\mathrm{Ag}-\mathrm{ZnO}$ nanostructures were characterized by using various characterization techniques, which revealed the large-scale synthesis of well-crystalline nanostructures and successful incorporation of $\mathrm{Ag}$ ions in the $\mathrm{ZnO}$ matrix, showing excellent chemical sensing properties. $\mathrm{ZnO}$ was found to show a low value of the limit of detection, i.e., $2.175 \mu \mathrm{M} / \mathrm{L}$, for p-nitrophenol sensing; moreover, a sharp decrease in the limit of detection was observed with an increase in the concentration of silver ions, and the LOD value decreased to $0.669 \mu \mathrm{M} / \mathrm{L}$ for the $10 \%$ silver-doped zinc oxide. It is therefore concluded that Ag-doped $\mathrm{ZnO}$ shows a lower limit of detection as compared to pure $\mathrm{ZnO}$ for p-nitrophenol sensing. We observed a decrease in the particle size with an increasing Ag ion concentration, as well as the presence of silver also decreasing the electron hole recombination rate, which led to the enhancement of the surface area and Ag also behaving as an electron scavenger. Hence, there was an increase in the chemical sensing efficiency owing to the separation of charge carriers, resulting in the restriction of their recombination. It is concluded that Ag-doped $\mathrm{ZnO}$ nanostructures are promising candidates for the detection of p-nitrophenol.

Supplementary Materials: The following are available online at http://www.mdpi.com/2227-9040/8/4/108/s1. Figure S1: EDS of pure ZnO nanoparticle, Figure S2: EDS of 1\% Ag-ZnO nanoparticle, Figure S3: EDS of 5\% Ag-ZnO nanoparticle, Figure S4. EDS of 10\% Ag-ZnO nanoparticle, Figure S5. Deconvoluted high-resolution XPS spectra for $1 \% \mathrm{Ag}-\mathrm{ZnO}$ powder sample.

Author Contributions: Experiments, D.T.; original draft writing, D.S., A.S., D.S.R.; data analysis, D.S., A.S., D.S.R.; review and editing, S.T. (Sourbh Thakur), N.T., T.T., M.A., S.T. (Sigitas Tamulevicius), S.K.S.; supervision, S.T. (Sourbh Thakur), D.S. All authors have read and agreed to the published version of the manuscript.

Funding: S.T. (Sourbh Thakur) is grateful for the financial support from the post-doctoral fellowship project No. 09.3.3-LMT-K712-02-0180 of measure 09.3.3-LMT-K-712 “Development of Scientific Competences of Scientists, other Researcher and Students through Practical Research Activities" (funding instrument: European Social Fund).

Conflicts of Interest: The authors declare no conflict of interest. 


\section{References}

1. Li, J.; Kuang, D.; Feng, Y.; Zhang, F.; Xu, Z.; Liu, M. A graphene oxide-based electrochemical sensor for sensitive determination of 4-nitrophenol. J. Hazard. Mater. 2012, 201, 250-259. [CrossRef] [PubMed]

2. Yin, H.; Zhou, Y.; Ai, S.; Liu, X.; Zhu, L.; Lu, L. Electrochemical oxidative determination of 4-nitrophenol based on a glassy carbon electrode modified with a hydroxyapatite nanopowder. Microchim. Acta 2010, 169, 87-92. [CrossRef]

3. Castillo, M.; Domingues, R.; Alpendurada, M.F.; Barcelo, D. Persistence of selected pesticides and their phenolic transformation products in natural waters using off-line liquid solid extraction followed by liquid chromatographic techniques. Anal. Chim. Acta 1997, 353, 133-142. [CrossRef]

4. Liu, W.-J.; Tian, K.; Jiang, H.; Yu, H.-Q. Harvest of $\mathrm{Cu}$ NP anchored magnetic carbon materials from Fe/Cu preloaded biomass: Their pyrolysis, characterization, and catalytic activity on aqueous reduction of 4-nitrophenol. Green Chem. 2014, 16, 4198-4205. [CrossRef]

5. Mulchandani, P.; Hangarter, C.M.; Lei, Y.; Chen, W.; Mulchandani, A. Amperometric microbial biosensor for p-nitrophenol using Moraxella sp.-modified carbon paste electrode. Biosens. Bioelectron. 2005, 21, 523-527. [CrossRef] [PubMed]

6. Li, S.; Du, D.; Huang, J.; Tu, H.; Yang, Y.; Zhang, A. One-step electrodeposition of a molecularly imprinting chitosan/phenyltrimethoxysilane/AuNPs hybrid film and its application in the selective determination of p-nitrophenol. Analyst 2013, 138, 2761-2768. [CrossRef]

7. Rawajfih, Z.; Nsour, N. Characteristics of phenol and chlorinated phenols sorption onto surfactant-modified bentonite. J. Colloid Interface Sci. 2006, 298, 39-49. [CrossRef] [PubMed]

8. Schultz, B. Determination of 4-aminophenol in water by high-performance liquid chromatography with fluorescence detection. J. Chromatogr. A 1984, 299, 484-486. [CrossRef]

9. Niazi, A.; Yazdanipour, A. Spectrophotometric simultaneous determination of nitrophenol isomers by orthogonal signal correction and partial least squares. J. Hazard. Mater. 2007, 146, 421-427. [CrossRef]

10. Nistor, C.; Oubiña, A.; Marco, M.-P.; Barceló, D.; Emnéus, J. Competitive flow immunoassay with fluorescence detection for determination of 4-nitrophenol. Anal. Chim. Acta 2001, 426, 185-195. [CrossRef]

11. Fischer, J.; Barek, J.; Wang, J. Separation and detection of nitrophenols at capillary electrophoresis microchips with amperometric detection. Electroanal. Int. J. Devoted Fundam. Pract. Asp. Electroanal. 2006, 18, 195-199. [CrossRef]

12. Kuban, P.; Berg, M.; García, C.; Karlberg, B. On-line flow sample stacking in a flow injection analysis-capillary electrophoresis system: 2000-fold enhancement of detection sensitivity for priority phenol pollutants. J. Chromatogr. A 2001, 912, 163-170. [CrossRef]

13. Singh, S.; Kumar, N.; Kumar, M.; Agarwal, A.; Mizaikoff, B. Electrochemical sensing and remediation of 4-nitrophenol using bio-synthesized copper oxide nanoparticles. Chem. Eng. J. 2017, 313, 283-292. [CrossRef]

14. Tang, Y.; Huang, R.; Liu, C.; Yang, S.; Lu, Z.; Luo, S. Electrochemical detection of 4-nitrophenol based on a glassy carbon electrode modified with a reduced graphene oxide/Au nanoparticle composite. Anal. Methods 2013, 5, 5508-5514. [CrossRef]

15. Ghazizadeh, A.J.; Afkhami, A.; Bagheri, H. Voltammetric determination of 4-nitrophenol using a glassy carbon electrode modified with a gold-ZnO-SiO 2 nanostructure. Microchim. Acta 2018, 185, 296. [CrossRef]

16. Negi, K.; Kumar, M.; Chauhan, M.S. Solution combustion synthesis of $\mathrm{CeO}_{2} / \mathrm{ZnO}$ nano-composite as a potential scaffold for detection and degradation of p-nitrophenol. Mater. Chem. Phys. 2019, 226, 59-65. [CrossRef]

17. Rahman, M.M.; Wahid, A.; Alam, M.M.; Asiri, A.M. Efficient 4-Nitrophenol sensor development based on facile $\mathrm{Ag} @ \mathrm{Nd}_{2} \mathrm{O}_{3}$ nanoparticles. Mater. Today Commun. 2018, 16, 307-313. [CrossRef]

18. Singh, K.; Ibrahim, A.A.; Umar, A.; Kumar, A.; Chaudhary, G.R.; Singh, S.; Mehta, S.K. Synthesis of $\mathrm{CeO}_{2}-\mathrm{ZnO}$ nanoellipsoids as potential scaffold for the efficient detection of 4-nitrophenol. Sens. Actuators B Chem. 2014, 202, 1044-1050. [CrossRef]

19. Umar, A.; Chauhan, M.S.; Chauhan, S.; Kumar, R.; Sharma, P.; Tomar, K.J.; Wahab, R.; Al-Hajry, A.D. Singh, Applications of $\mathrm{ZnO}$ nanoflowers as antimicrobial agents for Escherichia coli and enzyme-free glucose sensor. J. Biomed. Nanotechnol. 2013, 9, 1794-1802. [CrossRef] [PubMed]

20. Fangli, Y.; Peng, H.; Chunlei, Y.; Shulan, H.; Jinlin, L. Preparation and properties of zinc oxide nanoparticles coated with zinc aluminate. J. Mater. Chem. 2003, 13, 634-637. [CrossRef] 
21. Wang, L.; Muhammed, M. Synthesis of zinc oxide nanoparticles with controlled morphology. J. Mater. Chem. 1999, 9, 2871-2878. [CrossRef]

22. Singh, K.; Mehta, S.K. Luminescent $\mathrm{ZnO}$ quantum dots as an efficient sensor for free chlorine detection in water. Analyst 2016, 141, 2487-2492. [CrossRef] [PubMed]

23. Singh, K.; Mehta, S.K. Utilization of ZnO Nanoflowers as Efficient Electrochemical Catalyst for the Oxidation of Hydrazine. Sens. Lett. 2015, 13, 1002-1006. [CrossRef]

24. Kumar, R.; Umar, A.; Rana, D.S.; Sharma, P.; Chauhan, M.S.; Chauhan, S. Fe-doped ZnO nanoellipsoids for enhanced photocatalytic and highly sensitive and selective picric acid sensor. Mater. Res. Bull. 2018, 102, 282-288. [CrossRef]

25. Kumar, R.; Rana, D.; Umar, A.; Sharma, P.; Chauhan, S.; Chauhan, M.S. Ag-doped ZnO nanoellipsoids: Potential scaffold for photocatalytic and sensing applications. Talanta 2015, 137, 204-213. [CrossRef]

26. Ahmed, S.A. Structural, optical, and magnetic properties of Mn-doped ZnO samples. Results Phys. 2017, 7, 604-610. [CrossRef]

27. Lupan, O.; Chow, L.; Ono, L.K.; Cuenya, B.R.; Chai, G.; Khallaf, H.; Park, S.; Schulte, A. Synthesis and characterization of Ag-or Sb-doped ZnO nanorods by a facile hydrothermal route. J. Phys. Chem. C 2010, 114, 12401-12408. [CrossRef]

28. Macias-Montero, M.; Borras, A.; Saghi, Z.; Romero-Gomez, P.; Sanchez-Valencia, J.R.; Gonzalez, J.C.; Barranco, A.; Midgley, P.; Cotrino, J.; Gonzalez-Elipe, A.R. Superhydrophobic supported Ag-NPs@ZnO-nanorods with photoactivity in the visible range. J. Mater. Chem. 2012, 22, 1341-1346. [CrossRef]

29. Liu, H.R.; Shao, G.X.; Zhao, J.F.; Zhang, Z.X.; Zhang, Y.; Liang, J.; Liu, X.G.; Jia, H.S.; Xu, B.S. Worm-like $\mathrm{Ag} / \mathrm{ZnO}$ core-shell heterostructural composites: Fabrication, characterization, and photocatalysis. J. Phys. Chem. C 2012, 116, 16182-16190. [CrossRef]

30. Sangpour, P.; Hashemi, F.; Moshfegh, A.Z. Photoenhanced degradation of methylene blue on cosputtered $\mathrm{M}: \mathrm{TiO}_{2}(\mathrm{M}=\mathrm{Au}, \mathrm{Ag}, \mathrm{Cu})$ nanocomposite systems: A comparative study. J. Phys. Chem. C 2010, 114, 13955-13961. [CrossRef]

31. Tarwal, N.L.; Patil, P.S. Enhanced photoelectrochemical performance of Ag-ZnO thin films synthesized by spray pyrolysis technique. Electrochim. Acta 2011, 56, 6510-6516. [CrossRef]

32. Ahmad, K.S.; Jaffri, S.B. Phytosynthetic Ag doped ZnO nanoparticles: Semiconducting green remediators. Open Chem. 2018, 16, 556-570. [CrossRef]

33. Kumar, R.; Rana, D.; Umar, A.; Sharma, P.; Chauhan, S.; Chauhan, M.S. Iron-doped ZnO nanoparticles as potential scaffold for hydrazine chemical sensor. Sens. Lett. 2014, 12, 1273-1278. [CrossRef]

34. Wöll, C. The chemistry and physics of zinc oxide surfaces. Prog. Surf. Sci. 2007, 82, 55-120. [CrossRef]

35. Kunat, M.; Becker, T.; Burghaus, U.; Wöll, C. Stability of the polar surfaces of ZnO: A reinvestigation using He-atom scattering. Phys. Rev. B 2002, 66, 081402. [CrossRef]

36. Alenezi, M.R.; Alshammari, A.S.; Jayawardena, K.I.; Beliatis, M.J.; Henley, S.J.; Silva, S.R.P. Role of the exposed polar facets in the performance of thermally and UV activated $\mathrm{ZnO}$ nanostructured gas sensors. J. Phys. Chem. C 2013, 117, 17850-17858. [CrossRef]

37. Hanagodimath, S.M.; Evale, B.G.; Manohara, S.R. Nonlinear fluorescence quenching of newly synthesized coumarin derivative by aniline in binary mixtures. Spectrochim. Acta A Mol. Biomol. Spectrosc. 2009, 74, 943-948. [CrossRef]

38. Marinoiu, A.; Raceanu, M.; Andrulevicius, M.; Tamuleviciene, A.; Tamulevicius, T.; Nica, S.; Bala, D.; Varlam, M. Low-cost preparation method of well dispersed gold nanoparticles on reduced graphene oxide and electrocatalytic stability in PEM fuel cell. Arab. J. Chem. 2020, 13, 3585-3600. [CrossRef]

39. Ratautas, K.; Andrulevičius, M.; Jagminienè, A.; Stankevičienè, I.; Norkus, E.; Račiukaitis, G. Laser-assisted selective copper deposition on commercial PA6 by catalytic electroless plating-Process and activation mechanism. Appl. Surf. Sci. 2019, 470, 405-410. [CrossRef]

40. Sharma, P.; Rana, D.S.; Umar, A.; Kumar, R.; Chauhan, M.S.; Chauhan, S. Synthesis of cadmium sulfide nanosheets for smart photocatalytic and sensing applications. Ceram. Int. 2016, 42, 6601-6609. [CrossRef]

41. Sharma, P.; Rana, D.S.; Umar, A.; Kumar, R.; Chauhan, M.S.; Chauhan, S. Hexagonal cadmium oxide nanodisks: Efficient scaffold for cyanide ion sensing and photo-catalytic applications. Talanta 2016, 153, 57-65. [CrossRef] 
42. Othman, A.; Hayat, A.; Andreescu, S. Eu-Doped Ceria Nanocrystals as Nanoenzyme Fluorescent Probes for Biosensing. ACS Appl. Nano Mater. 2018, 1, 5722-5735. [CrossRef]

43. Chu, L.; Han, L.; Zhang, X. Electrochemical simultaneous determination of nitrophenol isomers at nano-gold modified glassy carbon electrode. J. Appl. Electrochem. 2011, 41, 687-694. [CrossRef]

44. Ahmad, N.; Alam, M.; Wahab, R.; Ahmad, J.; Ubaidullah, M.; Ansari, A.A.; Alotaibi, N.M. Synthesis of $\mathrm{NiO}-\mathrm{CeO}_{2}$ nanocomposite for electrochemical sensing of perilous 4-nitrophenol. J. Mater. Sci. Mater. Electron. 2019, 30, 17643-17653. [CrossRef]

45. Arvinte, A.; Mahosenaho, M.; Pinteala, M.; Sesay, A.-M.; Virtanen, V. Electrochemical oxidation of p-nitrophenol using graphene-modified electrodes, and a comparison to the performance of MWNT-based electrodes. Microchim. Acta 2011, 174, 337-343. [CrossRef]

46. Kumar, V.; Singh, K.; Panwar, S.; Mehta, S.K. Green synthesis of manganese oxide nanoparticles for the electrochemical sensing of p-nitrophenol. Int. Nano Lett. 2017, 7, 123-131. [CrossRef]

Publisher's Note: MDPI stays neutral with regard to jurisdictional claims in published maps and institutional affiliations.

(C) 2020 by the authors. Licensee MDPI, Basel, Switzerland. This article is an open access article distributed under the terms and conditions of the Creative Commons Attribution (CC BY) license (http://creativecommons.org/licenses/by/4.0/). 